\title{
Applications of Nano Electrical Machines used in Ball mills for Nano and Pyro Technology Based Industries in Sivakasi
}

\author{
S. Geethadevi \\ Dept. of EEE \\ Aurora Scientific and \\ Technological Institute \\ Uppal, Hyderabad, India
}

\author{
Dr. C. Pugazhendhi \\ Sugumaran \\ Dept. of EEE \\ Division of High Voltage \\ Engineering, College of \\ Engineering, Guindy \\ Anna University, Chennai \\ India
}

\author{
M. Rajkumar \\ Dept. of EEE \\ Dhanalakshmi Srinivasan \\ College of Engineering and \\ Technology \\ Mamallapuram \\ Chennai, India
}

\author{
D. Edison Selvaraj \\ M. Rajmal Joshi \\ Dept. of EEE \\ Panimalar Engineering College \\ Chennai, India
}

\section{J.Ganesan}

Dept. of EEE

Sree Sowdambika College of

Engineering

Aruppukottai, India
K. Mohanadasse

Dept. of EEE

St. Joseph's College of Engineering, Chennai, India

\begin{abstract}
Nano fillers play a vital role in increasing the performance of different types of motors. In recent days, nano technology shows a tremendous improvement in the manufacture of high performance electronic devices and circuits, electrical apparatuses and equipment. In this paper, a wide literature survey was done on the filled of nano dielectrics and nano coated motors. Comparison of different nano fillers coated motors was done to show which motor was having superior performance characteristics compared to other motors. Based on the literature survey on the previous research works carried out in the field of applications of nano technology in the coating of nano fillers to the enamel used in the motors. Ball mills are using three phase induction motors for the mechanical operations. Ball mills are used to manufacture the nano powders used for both the nano technology and pyro technology. Industries should be well equipped with safety devices to avoid the fire accidents. Industries should follow the safety norms to avoid the fire accidents. Pyro technology based research centre was located in Sivakasi to understand and motivate the engineers, people to make an interest towards Pyro industries and to train the persons about the safety measures while working with the nano pyro powders used in the nano pyro industries. The powders used here are always in the nano range. But, the people were unaware of this technique. So, this paper will create some knowledge to the people who are working in nano pyro based industries present in Sivakasi. Sivakasi was an industrial city located in South India having more than 15000 nano pyro based industries. So, this paper will educate the engineers, managers and the persons who are all associated with these industries.
\end{abstract}

Keywords: Motor, nano fillers, SEM, Ball mill, Efficiency, Harmonics, EMI

\section{INTRODUCTION}

The Nano electrical machine design involves the application of nano science and nano technology to produce

1. Cost effective

2. Durable

3. High Quality and

4. High Efficiency machines
The nano electrical machines are designed as per standard specifications. The requirements like low cost and high quality are conflicting in nature and so a compromise should be done between them [1]. The nano electrical machines are classified into

1. Static and

2. Dynamic Machines 
Nano transformer is a static machine whereas nano motors and generator are dynamic machines. Nano transformer converts electrical energy from one level to another level without changing frequency. It is a static electromagnetic device. It consists of two or more windings which link with a common magnetic field. An iron core serves as a path for magnetic flux. The basic constructional elements of a nano transformer are

\section{Windings \\ 2. Core \\ 3. Tank \\ 4. Cooling tubes and \\ 5. Insulation}

It has two windings. One is called as high voltage winding and another is called as low voltage winding. One of the winding is connected to supply and it is called as primary. Another winding is connected to load and it is called secondary. The different types of transformer are

\section{Core type \\ 2. Shell type \\ 3. Berry type}

In core type, the windings surrounded the core whereas in shell type, the core surrounds the windings. The core and winding assembly is housed in the tank. Nano filler mixed is used for insulation. Cooling tubes are provided around the tank surface in order to increase the effective cooling surface [2]. Nano rotating machines convert electrical energy to mechanical energy or vice-versa. The conversion takes place through magnetic field. The required magnetic field is produced by an electromagnet which requires a core and winding. The basic principle of operation is governed by faradays law of electromagnetic induction. Every rotating machines has the following quantities

1. Field flux

2. Armature flux

3. Voltage

4. Current

5. Mechanical force

In generator, the armature is rotated by a mechanical force inside a magnetic field or the magnetic field is rotated by keeping armature stationary. By faradays law of electromagnetic induction an emf is induced in the armature. When the generator is loaded, the armature current flows which produces armature magnetic field. Hence, in a generator, by the presence of a magnetic field and mechanical force, armature magnetic field is produced.

The mechanical force developed by the motor is due to the reaction of two magnetic fields. A current carrying conductor has a magnetic field around it. When it is placed in armature magnetic field, it experiences a mechanical force due to the reaction of two magnetic fields. Hence in a motor by the presence of two magnetic fields, a mechanical force is developed.

Any rotating machine requires two magnetic fields. One is stationary and another one is revolving. Hence a rotating machine will have a stationary and rotating electromagnet, each consisting of a core and winding. The stationary electromagnet is called stator and the rotating electromagnet is called is called rotor.

The basic constructional elements of rotating machine are stator and rotor. In DC machines, the stator consists of filed core and windings. The rotor consists of armature core and windings. The rotor consists of filed core and windings. The basic constructional elements of DC machines are

\author{
1. Stator \\ i. Yoke \\ ii. Field pole \\ iii. Pole shoe \\ iv. Field winding \\ v. Inter pole \\ 2. Rotor \\ i. Armature core \\ ii. Armature winding \\ iii. Commutator
}

3. Brush and Brush holder

CNT based materials can be used for brushes.

\section{Insulation}

Enamel (or) varnish is used to coat windings to provide insulation between the windings. Enamelled copper wires are used as conductors. Hence, enamel is used for two purposes

1. Coating of the conductors

2. Coating of the windings

In nano coated motors, the enamel mixed with nano fillers is used for the coating of the windings. The basic constructional elements of squirrel cage induction motors are

Stator
i. Frame
ii. Stator core
iii. Stator winding
i. Rotor core
ii. Rotor bars
iii. End windings

Rotor

\section{ALGORITHM FOR THE DESIGN OF NANO MOTORS}

1. Manufacture the nano fillers by using ball mill method [3]

2. Augment the particle size by using SEM analysis [4]

3. Mix the nano fillers and the enamel by ultrasonic vibrators

4. Coat and impregnate the windings of different types of motors with the various nano fillers [5]

5 . Test the different nano coated motors

6. Compare the results

7. Justify the nano coated motor which is having the superior characteristics when compared to other motors [6].

\section{EXPERIMENTAL WORKS NEEDED FOR THE DESIGN OF NANO MOTORS}

1.Ball mill was used to manufacture the nano fillers used in nano coated motors used in Textile industries. $\mathrm{Al}_{2} \mathrm{O}_{3}, \mathrm{SiO}_{2}$, $\mathrm{TiO}_{2}, \mathrm{ZrO}_{2}, \mathrm{ZnO}, \mathrm{SiC}$ were used as nano fillers used in nano coated motors [7].

2. SEM was used to augment the particle size of fillers before and after Ball milling process.

3. Ultra sonic vibration process was used to mix the enamel and nano fillers [8]

4. Nano filler mixed enamel was used as the coating and impregnation for the windings of the motor [9].

5. Different types of testing were conducted to determine the performance of the nano coated motor [10]. They were

a. Direct loading

b. Temperature test 
c. Harmonics Measurement

d. EMI Measurement

6. The readings should be taken and compared between the different types of nano coated motors used in Textile mills.

\section{ADVANTAGES OF NANO COATED MOTORS}

The following are the advantages of nano coated motors [11]:

1. Higher efficiency

2. Wide operating temperature range

3. Reduced Harmonics

4. Reduced EMI

5. Increased life time

6. Reduced losses

7. Improved Cooling

8. Reduced noise

9. Lesser amount of powder to produce large output

10. The quality of the industries will be increased by these motors.

\section{LIMITATIONS OF NANO COATED MOTORS}

The most important drawbacks of nano coated motors are:

1. Powder manufacturing is time consuming

2. Expensive equipments were employed for synthesis and characterization of nano fillers

\section{CONCLUSIONS}

This paper shows the wide knowledge required for the design of nano coated motors used in Nano Pyro Industries located in the South Indian city called as Sivakasi. The following tests should be conducted for the design and checking of the nano coated motors:

1. SEM Results

2. Direct loading

Load test was used to find the performance of the motor in terms of efficiency

3. Temperature test

4. Harmonics Measurement

5. EMI Measurement

\section{ACKNOWLEDGEMENT}

We express our sincere thanks to the God, the Almighty, and Lord Jesus Christ. We express our gratitude towards our Tamil Scientist Dr. A.P.J. Abdul Kalam. We express our deep heart feelings towards His death.

\section{REFERENCES}

[1] Edison selvaraj. D, et.al Applications of Nano Technology in Pyro Industries located in Sivakasi, International Journal of Science and Engineering Applications Volume 4 Issue 4, 2015.
[2] Edison Selvaraj. D, et.al "Estimation of Losses on 3Ф Nano Coated Induction Motor" Applied Mechanics and Materials Vol.666 (2014) pp. 213 217 (2014) Trans Tech Publications, Switzerland.

[3] Edison Selvaraj. D, Pugazhendhi Sugumaran. C, Lieutenant Ganesan. J, Ramathilagam. J, "Analysis of Dielectric and Thermal Properties of Polyamide Enamel Filled with Carbon Nano tubes" International Journal of Nano science, Vol.12, Issue 3, June 2013.

[4] Edison Selvaraj, D., C. Pugazhendhi Sugumaran, and A. Sivaprakash "Characterization of Electrical and Thermal Properties of Enamel Filled with Carbon Nanotubes", Proceedings of the Third International Conference on Trends in Information, Telecommunication and Computing, Springer New York, 2013.

[5] Selvaraj, D. E., Priyan, S. S., Joshi, M. R., Sugumaran, C. P., Kannan, R., Raj, R. A., Kumar, B. M., Prakash, R., Ganesan, J., Krishnamoorthi, D., \& Kumar M. R, “A Review on The Nano Fillers Used for Electrical Apparatuses", Journal Club for Electrical Engineering (JCEE), Vol.1, Issue 1, pp 8 -17, Aug 2014.

[6] Selvaraj, E. D., Priyan, S. S., Joshi, M. R., Sugumaran, C. P., Kumar, B. A., Kumar, M. A., Kumar, S. A., Khan, A. H., Kannan, R., Ganesan, J., Kumar, R., Kumar S. D, "A Review on theFabrication Methods Used in Nano Technology for The Fabrication of Nano Fillers Used in Electrical Apparatuses", Journal Club for Electrical Engineering (JCEE), Vol.1, Issue 1, pp , Aug 2014.

Joshi MR Selvaraj DE, Kumar GS, Mohan BR, Sugumaran CP, Kumar RM, Ganesan J, “A Lecture Notes for Understanding the Fundamentals of Fabrication of Nano Fillers", Journal Club for Electrical Engineering (JCEE), Vol.1, Issue 2, pp 1 16, Oct 2014.

[8] Edison Selvaraj. D , Ruban Karthik. C, Arun. R, Geethadevi. S and Ganesan. J, "Energy Efficient Three Phase Squirrel Cage Induction Motor Fed AC Drives" in International Journal of Science and Engineering Applications, Vol.3, Issue2, pp.1821, 2014.

[9] Edison Selvaraj. D, Pugazhendhi Sugumaran. C. Dr. Shrikrishna V. Kulkarni, Sukumar Mishra, Ganesan. J, Raj Kumar.M, Geethadevi. S, "Energy efficient DC shunt motor fed drives" International Journal of Electrical and Electronic Science 2014; 1(1): 12-17.

[10] Edison Selvaraj. D, Pugazhendhi Sugumaran. C, Ganesan. J, Rajkumar. M, "Nano Filler Mixed EnamelCoated Single Phase Capacitor Run Induction Motor" in Global Journal of Researches 
International Journal of Science and Engineering Applications

Volume 4 Issue 5,2015, ISSN 2319-7560 (Online)

in Engineering, GJRE Volume

14

Issue 6 Version 1.0, pp.1-8, August 2014.

[11] Edison Selvaraj. D, Pugazhendhi Sugumaran. C, Krishnamoorthi. D, Raj Kumar. M, Ganesan. J, Geethadevi. S, Rajaram. K, Dinesh Kumar. S, "Improvement of Efficiency and Thermal Withstanding Capacity of Single Phase Induction Motor" in European Journal of Academic Essays 1(5): 10-15, 2014. 